\title{
Nuclear energy for sustainable development: SWOT analysis on Ghana's nuclear agenda
}

\author{
Ephraim Bonah Agyekum ${ }^{\mathrm{a}, *}$, Michael Nii Sanka Ansah ${ }^{\mathrm{b}}$, Kwame Bright Afornu ${ }^{\mathrm{b}}$ \\ a Department of Nuclear and Renewable Energy, Ural Federal University named after the first President of Russia Boris Yeltsin 620002, 19 Mira \\ Street, Ekaterinburg, Russia \\ ${ }^{\mathrm{b}}$ National Research Tomsk Polytechnic University, Lenin Avenue, 30, 634050, Tomsk, Russia
}

\section{A R T I C L E I N F O}

\section{Article history:}

Received 16 October 2019

Received in revised form 19 November 2019

Accepted 30 November 2019

Available online $\mathrm{xxxx}$

\section{Keywords:}

Nuclear power plant

Ghana

SWOT analysis

Sustainable energy

Financing model

\begin{abstract}
A B S T R A C T
The development of clean and sustainable energy around the world has become a necessity as a result of the negative effect energy generated from fossil fuel have on the environment. Ghana intends to add nuclear power to its generation mix by 2029. This paper uses the SWOT analysis tool to assess the internal strengths and weaknesses as well as the external opportunities and threats in the country relative to its nuclear power program. We found out that despite the country's effort towards meeting the requirements for the licensing, contracting, construction and operation of the facility, there are still some important loopholes which could delay the process. The research found out that Ghana has a lot of strengths and opportunities that makes an investment in nuclear power an economically viable option. However, issues such as porous security system, corruption, porous borders and policy discontinuity due to changes in political power are threats to the smooth implementation and operation of a nuclear power plant. The research therefore recommended to the government of Ghana to pay critical attention to some of these loopholes. We also looked at a particular weakness which is financing and provided some funding options for its development.
\end{abstract}

(c) 2019 The Authors. Published by Elsevier Ltd. This is an open access article under the CC BY license (http://creativecommons.org/licenses/by/4.0/).

\section{Introduction}

The availability of a reliable, clean and affordable energy is crucial to the development of every country. Research indicates that, there exists a direct correlation between poverty around the globe and the availability of reliable and cheap energy (Reddy et al., 2000; Agyekum et al., 2019). The industrial sector which is the engine of growth in any economy requires energy since it is a basic essential input. As a result, countries and communities with little or no access to electrical power tend to have no or less industrial enclaves, this means people who reside in that enclave will have no job opportunities. A huge percentage of Africans live below the poverty line, especially those in the rural communities mainly because of the lack of jobs (Kebede et al., 2010). Ghana has been facing energy crisis over the years as a result of increasing population, industrialization and urbanization. The government of Ghana has therefore planned to add nuclear energy to its energy generation. This idea was conceptualized by the first president of Ghana, Dr. Kwame Nkrumah in 1961 (Adu-Gyamfi et al., 2017).

Nuclear energy is a form of energy that is obtained through nuclear reaction, the reaction releases heat energy which heats

\footnotetext{
* Corresponding author.

E-mail address: agyekum@urfu.ru (E.B. Agyekum).
}

water into steam to turn steam turbines to produce electrical power. Nuclear energy can be obtained from fusion, fission or nuclear decay reactions (Meierding, 2013). It is seen as an alternative to energy generated from fossil fuels or hydrocarbons. Even though, nuclear energy is regarded as a physically imperfect substitute for transportation, it is potent, relative to electricity generation, which can be used to power vehicles and trains for transportation. Nuclear power can serve as a substitute for power plants that use fossil fuel in developed and developing countries around the world. The transition from conventional sources of energy to nuclear energy is expected to reduce demand pressures on crude oil and also protect the environment from greenhouse gas emissions (Anon, 2019a).

The Ghana Atomic Energy Commission (GAEC) and the State Atomic Energy Corporation of the Federation of Russia (ROSATOM), signed a Memorandum of Understanding in August 2015 to construct a nuclear power plant (NPP) in Ghana. The country is expected to purchase the Russian model VVER (water-water energetic reactor) with capacity ranging between 1000-1200 MW according to the signed agreement. The decision to integrate nuclear energy to the energy mix is not only limited to Ghana but some other African countries, in July 2015 ten African countries established the African Network for Enhancing Nuclear Power Program Development which is aimed at the 


$\begin{array}{ll}\text { Abbreviations } & \\ \text { GAEC } & \text { Ghana Atomic Energy Commission } \\ \text { NPP } & \text { Nuclear Power Plant } \\ \text { VVER } & \text { Water-Water Energetic Reactor } \\ \text { GWh } & \text { Gigawatt hour } \\ \text { VALCO } & \text { Volta Aluminum Company } \\ \text { MW } & \text { Megawatt } \\ \text { LCOE } & \text { Levelized Cost of Energy } \\ \text { NEA } & \text { Nuclear Energy Agency } \\ \text { IAEA } & \text { International Atomic Energy Agency } \\ \text { VRA } & \text { Volta River Authority } \\ \text { GNRA } & \text { Ghana Nuclear Regulatory Authority } \\ \text { SNAS } & \text { School of Allied and Nuclear Science } \\ \text { IMF } & \text { International Monetary Fund } \\ \text { GDP } & \text { Gross Domestic Product } \\ \text { GHG } & \text { Greenhouse Gas } \\ \text { GRIDCo } & \text { Ghana Grid Company Limited } \\ \text { NED } & \text { Northern Electricity Department } \\ \text { PURC } & \text { Public Utilities Regulatory Commission } \\ \text { ECG } & \text { Electricity Company of Ghana }\end{array}$

development of nuclear energy in those countries (Ramana and Agyapong, 2016).

In this current study, the SWOT analysis approach was adopted to investigate the strengths, weaknesses, opportunities and threats for the development of nuclear power in Ghana. Data for this analysis were obtained from existing literature, interviews and documents on nuclear energy projects around the world. This work is critical because there are still measures that are needed to be attended to, in order to avert or forecast any misfortune that may arise in the course of implementation, development and operation of the nuclear facility. Safety and cost are the most vital features for future introduction of a nuclear power plant. The organizational structure of the research is presented as follows: Section 1 covers the history and current status of the nuclear program in Ghana, views of the general public about the program and the country's electricity sector composition. Section 2 also covers the methodology adopted for the analysis. Section 3 presents the results and discussions of the SWOT analysis. Section 4 also presents some financing models for the development of the nuclear power sector. Section 5 covers the institutional set up for the energy sector and Section 6 concludes the research with some recommendations.

\subsection{Geographical location of Ghana}

Ghana can be located in West Africa, it shares boundaries with Burkina Faso to the north, Côte d'Ivoire to the west, eastern part with Togo and the Atlantic Ocean to the south. The country lies between latitudes $4^{\circ} 45^{\prime} \mathrm{N}$ and $11^{\circ} \mathrm{N}$, and longitudes $1^{\circ} 15^{\prime} \mathrm{E}$ and $3^{\circ} 15^{\prime} \mathrm{W}$. The total land mass of the country is about 239,460 $\mathrm{km}^{2}$ (Duku et al., 2011), and is divided into sixteen administrative regions. The country has several water bodies such as the Volta Lake, Ankobra, Pra, Oti among others which could be used to cool the nuclear facility.

\subsection{Electricity demand and current composition in Ghana}

Over $83.24 \%$ of Ghanaians are connected to electrical power second to south Africa in the sub-region (Medium Term Expenditure Framework (MTEF), 2018). Supply of power has however

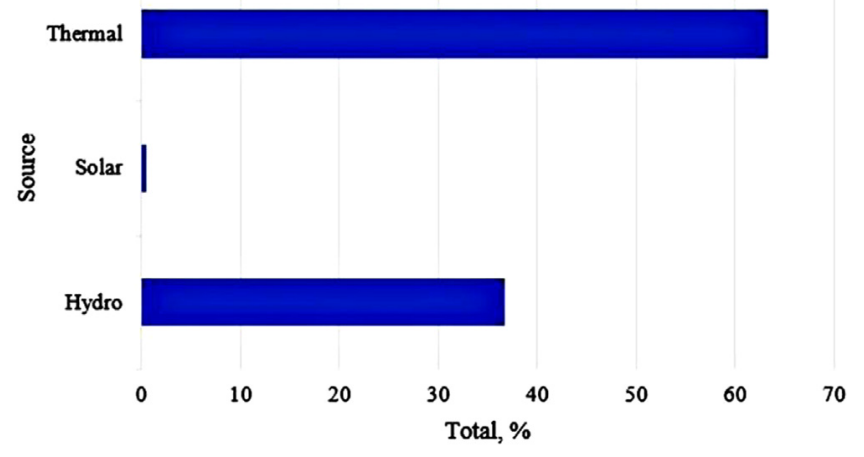

Fig. 1. Ghana's installed electricity composition by source (Energy Commission of Ghana Report, 2018).

been quite erratic in the country either as a result of lack of installed capacity or lack of money to buy fuel for the power plants. Demand for energy in the country has been increasing over the years as a result of increasing economic activities, industrialization, population growth and urbanization among others. The country's energy demand increased rapidly in the last decade from about $6367 \mathrm{GWh}$ in 2000 to about 10,129 GWh by 2016. The industrial sector in the year 2000 had a share of about $68 \%$ of electricity but reduced to about $45 \%$ in 2016 , representing an average decline of $2.6 \%$ annually (Diawuo et al., 2019). The residential sector however, increased its share from $23 \%$ to $39 \%$, the services sector also saw an increase from $9 \%$ to $16 \%$, in that same period indicating an average rise of $3.3 \%$ and $3.8 \%$ annually, respectively. The temporary shutdown of major energy-intensive projects such as the aluminum smelting company VALCO whose power demand is about $360 \mathrm{MW}$ caused the decline of electricity share for the industrial sector. The increase in share for the residential sector was also attributed to changing lifestyle as well as increasing ownership of domestic appliances during that period (Diawuo et al., 2019; Gyamfi et al., 2018). Ghana's installed electricity generation capacity available for grid supply stood at about 4310 MW at the end of 2017 (Energy Commission of Ghana Report, 2018). Generation from thermal power plants which runs on fossil fuel represents greater percentage of the total installed capacity. Fig. 1. shows the composition of the installed generation capacity for Ghana, the sector is largely dominated with thermal energy (fossil fuel) exposing the electricity sector to international prices of fuel.

\subsection{Comparison of cost of energy for nuclear and other form of energies}

Introduction of the $1200 \mathrm{MW}$ nuclear energy is expected to change the current scenario. The addition of nuclear energy to the generation mix will not only increase the installed capacity but also lead to a reduction in the emission of greenhouse gases into the environment which has a telling effect on lives. This technology (nuclear) unlike the conventional sources uses little uranium to generate power. Lazard's 2018 (version 12.0) estimation of levelized cost of energy (LCOE) for different energy sources indicated in Table 1 undoubtedly puts the LCOE for an NPP in an expensive position compared to the hydrocarbons and the renewables. However, it might not be so profitable in the context of environmental pollution particularly that of the fossils with the strict limitations of $\mathrm{CO}_{2}$ emissions. Also, the high uncertainty about energy policies could rule out certain technologies as a result of the high renumeration rates investors demand to recompense for the high level of perceived risks for those 
Table 1

Levelized Cost of Energy Comparison-Unsubsidized Analysis (Levelized Cost of Energy Comparison, 2019).

\begin{tabular}{ll}
\hline Type of technology & Levelized cost of energy, \$/MWh \\
\hline Alternative energy & \\
Solar PV - Rooftop Residential & $160-267$ \\
Solar PV - Community & $73-145$ \\
Solar thermal tower with storage & $98-181$ \\
Fuel cell & $103-152$ \\
Geothermal & $71-111$ \\
Wind & $29-56$ \\
Conventional energy & \\
Gas peaking & $152-206$ \\
Nuclear & $112-189$ \\
Coal & $60-143$ \\
Gas combined cycle & $41-74$ \\
\hline
\end{tabular}

technologies (Mari, 2014). The stochasticity of renewables such as solar and wind makes them disadvantaged over nuclear energy although they are relatively cheaper than the nuclear power.

\subsection{Views of the public on Ghana's NPP project and radioactive waste}

Nuclear energy development on the African continent has always invoked fears in people, and governments have had to abandon such projects despite the numerous benefits associated with such projects. Some of these concerns regarding the use of NPP are mostly misconceptions and exaggerations generally fueled by international politics. However, such risks did not deter other countries around the world from hosting such facilities. The over 50 years of commercial NPP operation across the globe have seen few accidents even though fatal, safety record of existing NPPs has improved over time as safety measures regarding its use have been strictly observed and upgraded (Adu-Gyamfi et al., 2017). Nonetheless, there has been a mix reaction about this technology particularly after the Fukushima incident in 2011. Clearly, the Fukushima Daiichi accident have led to several policy changes in the nuclear energy industry around the world, it has also resulted in the slow implementation and development of the technology, however, countries' policy re-evaluations of NPP as a result of the accident largely appear to have subsided according to the Nuclear Energy Agency (NEA) (2019).

Views on the implementation of the nuclear power program was collated on various university campuses and among workers in Ghana about the introduction of NPP. Results from the people shows majority are in support of the introduction, because of the need to completely eradicate the country's reoccurring power crisis. Others who were against its implementation also expressed their fear for nuclear power because they perceive nuclear as dangerous and that the country was not ready for it. Fig. 2 shows the results collated from the public about Ghana's nuclear energy agenda.

Nuclear waste is small in volume which is highly monitored and well confined compared to solid and toxic wastes generated by other fuel chains. The most radioactive waste from an NPP is the spent fuel, it can however, be re-processed and used as fuel for the plant. A policy for fuel and waste management (interim storage of the spent fuel and the final disposal of high-level waste) management will be developed by a Technology Assessment working group in the country. Ghana is not expected to play part in the management of the full fuel cycle according to authorities. The contract agreement for the development of the nuclear facility will include a clause that requires the supplier to ship the spent fuel back to their home country (Birikorang, 2012).

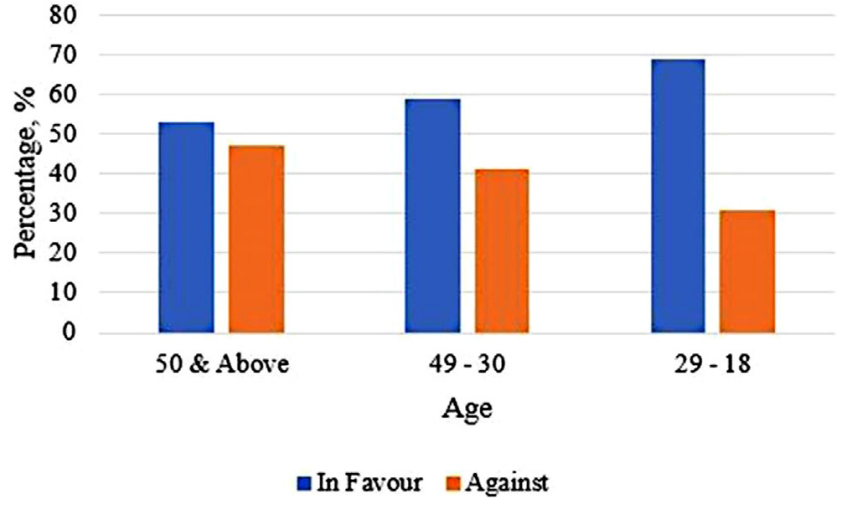

Fig. 2. Results on the Opinion Poll on the Implementation of an NPP (Birikorang, 2012).

\subsection{Roadmap to Ghana's nuclear energy development}

The vision to integrate nuclear energy into Ghana's generation mix dates back to the 1960s when the then government began the Kwabenya Nuclear Reactor Project in 1961. This led to the introduction of nuclear science into the country with the ultimate aim of exploring nuclear energy for the generation of electrical power for national development. In 1963, GAEC was established by an Act of Parliament (Act 204). GAEC was tasked to promote, develop and utilize nuclear energy for peaceful application purposes for the socio-economic advancement of the country (IAEA, 2018). The initial vision of constructing a 2 MW Soviet type research reactor was meant to help in the training of the needed manpower for the operation of a nuclear reactor in the future and the production of isotopes as well as neutron activation analysis. However, the nuclear program could not move on as it should because of several socio-economic and political factors. Ghana's quest to construct a research reactor was realized in 1994 when a 30-kW slowpoke reactor was built under a technical co-operation agreement between the government of the Republic of Ghana and the International Atomic Energy Agency (IAEA) (Ennison and Dzobo, 2018).

As a response to the country's increasing electric power demand resulting in power crisis, the government of Ghana in 2007 announced their intention to add nuclear power to the generation mix. The program has seen a lot of set-backs as a result of regime changes. However, a new road map announced by the Ministry of Environment, Science, Technology and Innovation indicates that it will take between 10 and 15 years for the realization of this vision (Anon, 2019b). The country can now expect nuclear energy by 2029 should plans proceed as scheduled (Anon, 2019c). An authority called the Nuclear Regulatory Authority has been setup to spearhead the nuclear power implementation process. The country has already passed all 19 infrastructural requirements needed for the commencement of the construction of the nuclear facility, this is the first of the three-phases required by the IAEA. The Volta River Authority (VRA), GAEC and the Bui Power Authority have been tasked to assist in the setting up of the structures required for the development of the nuclear power plant (NPP) (Anon, 2019c).

\subsection{Development of domestic regulatory formulation}

Countries who express interest to integrate nuclear power into their energy generation mix are required to develop their domestic policy and regulations for the sector. The IAEA has a framework for the development of an NPP that must be met by 
members who express interest. In formulating the needed nuclear infrastructure, there are some activities that are required to be completed. These activities can be divided into three developmental phases. The term "milestone" in this case refers to the conditions that must be met to show a successful completion of a particular phase. These phases have to be completed to enable the country involve to order, license, construct and operate an NPP. Experience shows that the period between consideration and operation of the first NPP takes about 10-15 years. The three developmental phases are as follows (Anon, 2019d):

- Phase 1 - consideration before a decision to introduce the nuclear power program is taken.

- Phase 2 - Preparatory work for the contracting as well as construction of an NPP after a policy decision has been made, during this stage, important organizations, regulatory and legal frameworks are formed.

- Phase 3 - Activities leading to contracting, licensing as well as construction of the NPP are undertaken.

The accomplishment of each phase is marked by a specific milestone at which point a decision can be made to proceed to the succeeding phase. These milestones are as follows (Anon, 2019d):

- Milestone 1: ready to make a knowledgeable commitment to the program;

- Milestone 2: Ready to invite bids or negotiate a contract for the first NPP;

- Milestone 3: Ready to commission and operate the first NPP.

\section{Methodology}

The SWOT analytical tool is tool for evaluating the strengths and weaknesses of an intended project, as well as the opportunities and the possible threats the project could face. SWOT analysis is important to an investor to assist in decision making, it can be used at personal or organization levels. Findings from a SWOT analysis helps companies build upon their strengths, realize new opportunities as well as work towards the minimization or elimination of any possible threat to the business (Phadermrod et al., 2019). The SWOT analytical tool is widely accepted by researchers in the energy sector for energy planning. Ishola et al. (2019), used the SWOT analytical tool to assess Nigeria's nuclear exploration agenda. Kamran et al. (2020) also conducted a research on Pakistan's renewable energy sector using the SWOT analytical tool. Furthermore, a comprehensive review in the context of possible advancement in technology and also the potential for East Asian countries including South Korea, Japan, and Taiwan to export green energy was conducted using the SWOT analytical tool (Chen et al., 2014). Also, a study was conducted using SWOT analysis to assess Africa's photovoltaic solar power in comparison with China (Lei et al., 2019). Another study also used SWOT analyses to evaluate Macedonia's national energy sector for sustainable energy development (Markovska et al., 2009). In order to attract investors into Tunisia's renewable energy market, a SWOT analysis was conducted to conclude on the key issues and factors to be taken to help develop the sector (Hamami et al., 2015). This analytical tool has some pluses: it comes with little or no cost - it can be performed by anyone who understands the specific field it is being applied, and it also focusses on the critical factors which could affect the smooth implementation of a project or business. However, this analytical tool also has some limitations such as the following: does not provide alternative solutions or decisions, prioritize issues, produces lots of information, nonetheless, not all might be useful, and it can also produce several ideas but cannot help choose the optimum idea (Anon, 2019e). This research is first of its kind for the Ghanaian nuclear energy sector and is expected to help inform decision making for the sector.
Table 2

SWOT analysis quadrant for the development of nuclear power plant in Ghana. Internal factors

\begin{tabular}{|c|c|}
\hline Strengths $(+)$ & Weaknesses (-) \\
\hline $\begin{array}{l}\text { 1. Tight national laws and regulatory } \\
\text { framework }\end{array}$ & 1. Poor grid system \\
\hline 2. Availability of experienced workforce & 2. Poor maintenance culture \\
\hline 3. Potential of uranium deposits & 3. Lack of investment will \\
\hline 4. Minor history of seismic events & $\begin{array}{l}\text { 4. Lack of adequate } \\
\text { financing }\end{array}$ \\
\hline \multicolumn{2}{|l|}{ External factors } \\
\hline Opportunities $(+)$ & Threats (-) \\
\hline 1. Increasing energy demand & 1. Dominance of fossil fuels \\
\hline 2. Regional interconnection & 2. Porous security system \\
\hline $\begin{array}{l}\text { 3. Increasing global awareness of climate } \\
\text { change }\end{array}$ & 3. Corruption \\
\hline 4. Availability of foreign investors & $\begin{array}{l}\text { 4. Discontinuity of energy } \\
\text { policies }\end{array}$ \\
\hline
\end{tabular}

\section{Results and discussions}

\subsection{SWOT analysis for the development of nuclear energy in Ghana}

This section presents a detail analysis on some factors considered in this study. The framework for the evaluation is represented in a quadrant form as indicated in Table 2 which will be discussed in detail in the subsequent sections.

\subsection{Strength analysis}

\subsubsection{Tight national laws and regulatory framework}

The peaceful use of nuclear energy - as well as all the potential it comes with for humankind - are paradoxically often perceived in juxtaposition with the possibility of the proliferation of nuclear wars and weapons. These various perceptions are comprehensible: the materials, knowledge and expertise required to produce nuclear weapons are generally indistinguishable from those needed to conduct nuclear research as well as produce nuclear power. Due to this, the international community's focus is to guarantee the peaceful use of nuclear energy (El Baradei et al., 1995). For this reason, Ghana has set up the Ghana Nuclear Regulatory Authority (GNRA) to oversee the regulatory aspect of the program. The GNRA is responsible for licensing of persons and institutions who manufacture, purchase, sell, store, import or export, use, or dispose of any kind or form of radioactive material or irradiating device, or any other source of ionizing radiation (Nuclear Regulatory Authority of Ghana, 2019). Ghana through GAEC has ratified several international conventions and codes. The country also has laws that are aimed at the development of nuclear power for peaceful purposes, some of the laws are as follows (IAEA, 2018):

- Laws establishing institutions tasked with different responsibilities relative to nuclear energy,

- Civil nuclear liability,

- Roles of national government, local government, and stakeholders,

These laws and regulations position the country on the path to the development of an NPP.

\subsubsection{Availability of experienced workforce}

The impetus to safeguard the peaceful use of an NPP requires experienced men and women for the job. Ghana have over the years invested a lot of capital in the training of human resources. The country has functional institutions such as the School of Allied and Nuclear Sciences (SNAS) which runs programs in the field of nuclear energy at both Masters and PhD levels, the Nuclear 
Power Institute as well as the GNRA. The 25 years' experience in the use of nuclear research reactor which is a miniature of an NPP also puts the country above it peers relative to the use of nuclear facilities. SNAS is now a training hub for not only Ghanaians but also several other nationals in the field of nuclear energy (Nyarko et al., 2009).

\subsubsection{Potential of uranium deposits}

The availability of resources at a specific site influences decision making when selecting a particular technology for energy generation. Though, in the case of nuclear power, the availability of fuel (uranium) at a particular location is not a key issue to be considered before building a plant, its availability at a particular location reduces cost of running such facilities. Currently, Ghana does not mine uranium, the country has made some discoveries in the area of uranium deposit but yet to confirm whether it is in commercial quantities. The government has since invited investors for a partnership for the development and exploration in the sector (New Uranium Mining Projects, 2019).

\subsubsection{Minor history of seismic events}

The country is located on the south-eastern part of the West Africa craton far away from major earthquakes zones which marks the lithospheric plate boundaries (Amponsah, 2004). However, Ghana is classified as medium, relative to earthquakes, this means the country has a $10 \%$ chance of experiencing a potentially-damaging earthquake (Anon, 2019f). The country however, have some minor history relative to earth tremors. Construction of an NPP requires a site free from severe earthquakes hence a special investigation of the geotectonic environment should be conducted on the various sites under consideration with the use of modern engineering equipment to avert any future misfortune after construction. Nevertheless, the country can still go into the development of an NPP without any major concern relative to earthquakes since greater percentage of the country's total land area is far from the earthquake prone areas. Nuclear power plants are also currently built to withstand some levels of earthquakes.

\subsection{Analysis of weaknesses}

\subsubsection{Poor grid system}

The deployment of a nuclear facility for the generation of electricity imposes some important requirements on the type of design capacity, operation and stability of the grid system. However, Ghana's electricity grid system is faced with lot of problems. According to research, the country has lost about 21.7\% of gross electricity generated within the last ten years through transmission and distributions. Transmission losses within that period accounted for $3.9 \%$ whiles distribution losses which also comprises commercial losses accounted for $16.2 \%$ yearly. These losses are as a result of the country's poor grid system mainly because of the obsolete nature of the facilities (Kumi, 2017). It is therefore necessary for authorities to carefully consider these requirements; this is because the physiognomies of the existing grid system can affect the size or capacity of reactor to be selected. This implies that Ghana's current grid system needs a significant upgrade and expansion to enable a successful introduction of an NPP otherwise an addition of a large NPP onto the system can risk the safety and economic operation of the NPP and the country's electricity system as a whole. Information from the IAEA indicates that for a country to safely and successfully integrate nuclear power into its generation mix, that country must have a grid system that is approximately ten times the capacity of the intended nuclear power plant to be constructed (Anon, 2019g). Ghana's current grid according to the Energy Commission's 2018 report is less than $5000 \mathrm{MW}$. Therefore, the introduction of a reactor with power capacity of $1200 \mathrm{MW}$ will cause a mismatch and affect power supply in the country.

\subsubsection{Poor maintenance culture}

Maintenance is a key feature in projecting quality management. It is required to ensure that infrastructure and other treasured assets continue to function and remain productive. Poor maintenance culture is a problem not only associated with Ghana but research indicates that it is a general problem in developing countries (Efobi and Anierobi, 2014). This poor culture cannot be accepted in the area of nuclear energy. Safety culture is a crucial factor to measure the preparedness of a country for the integration of nuclear energy into its power generation system. The idea of understudying safety principles dynamics is an accepted tool for enhancing human behavior to obtain an important improvement in the overall safety performance (Schöbel et al., 2017). The use of nuclear energy requires the highest form of safety and precaution, this is because, the slightest error can be lethal. It is therefore important for Ghana to consciously improve upon its maintenance culture if the country is to realize the vision of adding nuclear energy to its generation mix.

\subsubsection{Lack of investment will}

Ghana's roadmap to integrating nuclear power into its energy mix has seen several postponements as a result of lack of resolve by governments to invest in the sector. The lack of successive governments to take investment risk stalled its development for years since its launch by the first president of the republic in 1963. If the country wants to build such a facility, there will be the need to whip-up public support because a lack of consensus and support from the general public could unquestionably constrain the introduction of an NPP. It is therefore necessary to have a broad open discussion on the introduction of nuclear facility to arrive at a single national decision that will be binding on all governments. Getting a single national position can also motivate investors to invest in the sector.

\subsubsection{Lack of adequate financing}

One characteristic associated with nuclear energy is its high capital cost which results in higher sensitivity to interest rates. Even though the cost of constructing an NPP depends on the unique circumstances of each project and the geographic location, its per kilowatt cost range still remains higher than the conventional sources of energy such as natural gas (Barkatullah and Ahmad, 2017). Developing economies with higher gross domestic product (GDP) to debt ratio will not be able to solely finance the construction of an NPP since such economies mostly have very little fiscal space to borrow the huge amount of money required for the construction of an NPP. The situation where governments finance such projects still dominate, however, there are currently several financing models where the private sector is involved. Nevertheless, initial government support is key in financing an NPP project. Ghana's debt to GDP ratio is expected to hit $62 \%$ by close of 2019 according to the International Monetary Fund (IMF) (2019), this puts the country in a tight economic situation to be able to initiate the financing of an NPP amidst other pressing needs of the country.

\subsection{Analysis of opportunities}

\subsubsection{Increasing energy demand}

There is an increasing energy demand in the country in recent years, this is as result of the country's increasing population (average growth rate of $2 \%$ per year), industrialization and urban growth (average growth rate of $4 \%$ between 1980-2013) (Mensah et al., 2016). The consumption of electricity has been increasing in the residential, industrial and commercial sectors with an annual growth rate of over $10 \%$ in the last decade. This has put pressure on electricity generation. The nation's unsuppressed 
peak demand and energy growth rate between 2000 and 2009 were $44 \%$ and $100 \%$ respectively. The residential and commercial sectors have witnessed the highest growth rate (Gyamfi et al., 2018). This can be associated with increasing per capita income, grid connection, technological advancement and increasing income. Increasing income translates into the use of cleaner fuel such as electricity rather than the usual biomass for cooking at homes (Gyamfi et al., 2018). This has triggered the creation of a huge market in the electricity sector because of the increasing demand for electricity for homes. Quite a large number of Ghanaians are still without access to clean and affordable sources of energy and the integration of nuclear energy will provide electricity to such homes and businesses.

\subsubsection{Regional interconnection}

Despite challenges in the electricity sector as well as the short fall in supply, the country still exports power to its neighboring countries like Togo, Cote d'Ivoire, Burkina Faso and Benin. According to the Energy Commission's 2018 report, the country exported a total of $284 \mathrm{GWh}$ of electrical power to Benin and Togo. Approximately 57.5 GWh of electricity was also exported to Burkina Faso in 2017 (Energy Commission of Ghana Report, 2018). Countries in West Africa signed the West African Power Pool (WAPP) agreement in October 2008 which is aimed at developing facilities for the generation of energy for the various countries as well as interconnection of the various individual national grids to enhance power supply (Anon, 2019h). The nuclear energy program implementation organization (NEPIO) among its tasks is to access the country's grid and its interconnection with WAPP to develop a strategy for the export of nuclear power to WAPP. This is a great opportunity for Ghana's nuclear energy project.

\subsubsection{Increasing global awareness of climate change}

The need for a clean energy has become a global concern. All governments around the world are finding ways to generate energy that have less negative effect on the environment for today and future generation. This has opened up conversation about the addition of nuclear energy to various countries' energy mix. A number of African countries are therefore working towards the implementation of nuclear power. Ghana is not an exception; the government has been working hard to reduce the levels of pollution by supporting the introduction of nuclear and renewable energies.

\subsubsection{Availability of foreign investors}

Ghana's quest to add nuclear power to its generation mix has received a lot of interest from several countries. According to a statement made by the Minister of Energy, Science, Technology and Innovation, Professor Kwabena Frimpong Boateng during a Meet-the-Press section organized in Accra, countries such as Russia, France, United States, and China have all expressed their interest in the development of NPP for the country. They are all interested in collaborating with the Ghanaian government towards the realization of the nuclear energy project (Anon, 2019b).

\subsection{Analysis of threats}

\subsubsection{Dominance of fossil fuels}

The country's energy policies favor the use of fossil fuel which tends to impede the penetration of other possible alternative energies. For example, the Ghanaian government subsidizes fossil fuel for its people. However, in order to limit the negative effect of greenhouse gases (GHG) on the environment as a result of the continual use of fossil fuel, there is the need for countries to depart from the use of fossil fuel onto the path of clean energy. According to the IEA, phasing out the subsidies on fossil fuel by 2020 could lead to a 5\% reduction in emission of GHG. Fuel subsidies distort markets and hinders the development of competitive alternative energy, which leads to a reduction in the possibility of the needed capital investment (Crawford, 2019). Furthermore, policy and decision makers tend to give more attention to short-term growth of the economy rather than the long-term sustainable development, this discourages investors and business leaders from exploring new path (Lei et al., 2019).

\subsubsection{Porous security system}

The issue with safety and security has been the greatest concern when discussing the development of nuclear energy in developing countries. A plethora of explanations - particularly the porous boundaries of such countries has been the greatest concern, Ghana shares boundaries with three countries and also with the Gulf of Guinea, which are all possible entry routes into the country. Research shows that Ghana has a lot of illegal entries at it borders (Border Crossings, 2019). Several people enter the country without proper screening which is dangerous to the security and peace of the country particularly when there is increasing acts of terrorism in other countries in the sub-region, like Burkina Faso, Nigeria, Cote d'Ivoire among others. The lack of enough local expertise required for the operation of such facility is also a serious issue relative to the safety and security of such a complicated facility. Despite Ghana's 25-year experience in the use of a research reactor, most people are still skeptical about the smooth implementation and operation of the facility considering how deadly such a facility will be when there is an accident. The economic situation and priorities in most African countries including Ghana does not correspond with the rapidly changing technological, scientific and commercial setting in which crimes occur (Abeer Mohamed, 2019). Therefore, the country has lot of work to do to strengthen its security measures, should the plan of nuclear energy integration go through. It is important to educate the entire citizens to be security conscious particularly those at the border towns to help in informing the security services of any unusual entries. The Ghana Immigration Service also have a critical role in ensuring that the right people are given access to the country, it is therefore important to train and provide them with the necessary equipment to enable them do their work. There is the need to also upgrade and resource the country's police and intelligence system to be able to monitor proliferation related smuggling or trading at the country's borders.

\subsubsection{Corruption}

Transparency International defines corruption as "the misuse of entrusted power for private gain" (Anon, 2019i). Corruption is not only limited to public officials but also private personnel who have been entrusted with power, an official who awards a lucrative contract to a particular supplier instead of another in return for kickbacks is obviously corrupt. In the nuclear sector, access to sensitive materials - related technology and information also epitomizes entrusted power. Corruption is a key factor to nuclear proliferation even though it is under-recognized. Research indicates that with the exception of North Korea, almost all nuclear weapon programs of either terrorist groups or states in the past years were all enabled by corrupt people (Bunn, 2019). The success of a nuclear proliferation is usually as a result of information obtained from both insiders and outsiders through corrupt means. The effect of corruption is not only limited to nuclear proliferation but it also has a significant effect on the initial capital cost which eventually affect the LCOEs of such projects (Debnath and Mourshed, 2018). This is because projects that are awarded through restrictive tendering processes or sole 
sourced instead of open tendering are sometimes expensive and most of such projects are mostly awarded to cronies through dubious means. This raises the cost of energy production as a result of the expensive nature of the project. Ghana has been battling with corruption over the years, according to the Transparency International's July 2019 report, the country ranked 78 out of 180 countries relative to corruption perception index and 41 out of 100 for the perceived level of corruption in the public sector (Ghana: Corruption Perception Index, 2019). These results are not encouraging for the development of the country and also for the smooth implementation of such a huge investment. It scares investors from all sectors and its fight should not be limited to the government but it should be the responsibility of all citizens to fight this canker in order to create the enabling environment for development and peaceful implementation and operation of the nuclear power project.

\subsubsection{Discontinuity of energy policies}

Even though several African countries have formulated a series of policies for the development of their respective energy sector, the effective and consistent implementation of these policies encounter potential risks as a result of influences from both home and abroad (Arriola, 2009). Policy implementation uncertainties as a result of political regime changes is also a threat to such a huge investment. This is a huge problem in Ghana as several projects initiated by past governments across the country are left to rot when there is a change in political power. This does not promote development particularly in a country that is cash trapped and therefore requires that the country's resources are put to good use. It also increases the level of risks in the financing of huge investments which scares investors.

\section{Financing models for the construction of an NPP}

Financing a nuclear power plant has always been difficult for developing countries across the world, and the financing of such capital-intensive power projects have seen some significant changes within the last decades. The following financing options are available to be considered:

- Finance between Governments - this is a type of financing whereby the tendering is done through governmental arrangements. This option is usually in the form of loans and the success of it depends on the kind of bilateral cooperation between the participating governments. In this model, the host country gets the opportunity to get technical experience in the nuclear sector from the other country particularly when the other partner has that knowhow. It also gives the exporting country the opportunity to sell their product and expertise to other countries (Terlikowski et al., 2019).

- Vendor Financing - this model occurs when a vendor lends money to a customer who then uses the borrowed money to purchase the vendor's services or product (Anon, $2019 j$ ). It may take the form of a vendor equity, vendor arranged credit or vendor provided credit (Murphy, 2014). This model depends on the vendor's financial strength and market demands. An example of this model is the $€ 10$ billion Hungarian New Paks Project which is financed by ROSATOM through a 30-year interstate loan to construct two units of Russian reactor type VVER with a total capacity of 2,400 MW. The loan has a repayment period which covers 21 years of the plant's operation and it represents $80 \%$ of the projected total cost of the project (Barkatullah and Ahmad, 2017).
- Guaranteed long term electricity contractual arrangements - in this model, the payment stream for the Build-Own Transfer (BOT) or concession project for an independent power plant is secured through a Power Purchase Agreement (PPA). The agreement is signed between a purchaser "offtaker" (usually state-owned electricity utility in the host country) and an independent power producer (in this case, nuclear power) (Anon, 2019k). An example of this model is the Akkuyu nuclear power plant located in Turkey where Turkish Electricity Trade and Contract Corporation (TETAS) signed a contract to purchase electricity at a fixed price of 12.35 cents/kWh within a 15 -year period. The cost of project is expected to be paid from revenue from the PPA (Barkatullah and Ahmad, 2017).

\section{Ghana's National Energy Policy and electricity sector struc- ture}

Ghana's National Energy Policy, 2010, includes cross-cutting plans for the energy sector, it aims at managing the fast-growing energy demands for national development. The National Energy Policy summaries the goals, challenges and actions for the sector. The goals are generally ambitious but feasible. The Policy covers a wide spectrum of issues in the sector and challenges relating to the following areas: Power Sub-sector, Renewable Energy Subsector, Petroleum Sub-sector, Energy Efficiency and Conservation, Waste-to-Energy, Energy and Gender, Energy and Environment, as well as Managing the future of the sector. The country also plans to develop nuclear energy for electricity generation in the long term. The objective of this policy is to make Ghana a major exporter of electricity in the sub-region, which can be attained through increase capacity as well as the modernization of transmission and distribution infrastructure (National Energy Policy, 2010).

The electricity sector was until 1990 monopolized, the Volta River Authority (VRA) was in charge of both generation and transmission of electricity to all regions while the Northern Electricity Department (NED), a subsidiary of VRA was in charge of distribution for the northern sector. Distribution at the southern sector was the responsibility of the Electricity Company of Ghana. The VRA was divided into generation and transmission systems in the late 1990s during the power sector reforms, that opened up the market for the inclusion of Independent Power Producers (IPP) (Kumi, 2017). In order to safeguard the proper functioning of all players in the sector, and to create the needed favorable environment for protection and promotion of private sector investments and participation, a number of regulatory bodies have been created by Acts of Parliament. These establishments are the Public Utilities Regulatory Commission (PURC), Energy Commission and the National Petroleum Authority (NPA). The Energy Commission is responsible for the planning of the electricity and energy system expansion, and also advises the government on energy policy and strategy, and the licensing of operators (Kemausuor et al., 2011). The PURC is the main agency responsible for the setting up of consumer tariffs and service regulations. The NPA is also response for the regulations in the petroleum subsector. In the power sector the Ministry of Energy is responsible for: providing of power related technical and policy advice to the government, formulation and implementation as well as monitoring of policies in the energy sector, and management of power related programs including the national electrification scheme and supervision of the state-owned public electricity agencies such as the GRIDCo, VRA, and the ECG (Kemausuor et al., 2011). 


\section{Conclusion}

Ghana is faced with recurring power crisis as a result of either lack of capacity or lack of funds to purchase fuel to run its thermal power plants. The government has therefore decided to integrate nuclear power into the country's generation mix. This research, evaluates Ghana's preparedness for its nuclear power program using the SWOT analytical tool.

The strengths as evaluated puts the country in a stronger position for the implementation of the program, the 25-year experience in the use of nuclear research reactor gives the country the needed exposure relative to the management and operation of a nuclear facility. It is however, instructive to note that, the management of an NPP comes with a lot of responsibilities and for that matter, there is the need to get more experience hands to handle such a facility. This can be done through training of specialists for particular sectors of nuclear power plant. In order to leverage over the strengths, it is necessary for a continuous performance assessment of the country's nuclear energy policy.

A key weakness that need the attention of industry players is the poor maintenance culture of the Ghanaian people. This cannot be accepted in the area of a complicated facility such as an NPP, there is the need for a regular maintenance to secure the facility and lives. It is therefore essential to implement a clear policy that governs the use of procedures and handling of nonconformities from procedures, this policy should be clearly communicated to workers who handle very critical sections of the facility. This is expected to ensure the needed maintenance is conducted in a swift and appropriate manner in harmony with agreed maintenance policy and strategy.

The opportunity to have a viable nuclear power project in Ghana abounds, especially because of the regional interconnectivity program through WAPP. Investors have the chance to export electricity to Ghana's neighboring countries. Several countries have expressed their interest in the program partly because of the stable democracy in the country.

The threats found are general issues associated with developing countries. The security system of most developing countries is not as tight as those in developed economies. This is the source of fear and skepticism among several people relative to the readiness of such countries for nuclear power plants. The government of Ghana and other countries that finds themselves in similar category need to engage communities around the potential sites on the benefits and risks associated with such projects. There is the need to assure the general public that the introduction of nuclear power would not increase the proliferation of dangerous weapons. This is because the effect of the vigilance of inhabitants around the facility cannot be underestimated. It is clear that such areas will be classified as security zone and possibly closed cities or towns. However, it is important for Ghana to strengthen its security and intelligence operation system to create the safe environment for the deployment of an NPP. Ghana's current porous borders cannot support the safe implementation and operation of an NPP particularly in this era of increasing acts of terrorism in the sub-region. The dominance of fossil fuel also hinders investments into the nuclear energy sector, we recommend the removal of fuel subsidies and an introduction of a public policy to reduce the use of fossil fuel.

Finally, in the absence of adequate funding, nuclear energy is not an option for developing countries so this research discussed some possible financing arrangements that could be accessed for the development of such a huge capital-intensive project. As discussed under weaknesses, financing of an NPP has always been a difficult issue particularly for developing economies as a result of the high level of risks in those countries. The new financing models discussed above helps to diversify the risks which can enhance the prospect of financing in new countries.

\section{Declaration of competing interest}

The authors declare that they have no known competing financial interests or personal relationships that could have appeared to influence the work reported in this paper.

\section{CRediT authorship contribution statement}

Ephraim Bonah Agyekum: Conceptualization. Michael Nii Sanka Ansah: Writing - reviewing. Kwame Bright Afornu: Writ ing-editing.

\section{Funding}

None.

\section{References}

Abeer Mohamed, M.S., (Sudan) Encouraging Community Engagement as a Strategy to Strengthen Nuclear Security in our Borders. https://www.iaea. org/sites/default/files/16/12/2016_essay_competition_winner_essays.pdf. (Accessed 18 September 2019).

Adu-Gyamfi, S., Amakye-Boateng, K., Brenya, E., Yartey, H.T., Dramani, A., Adoteye, V.N., 2017. Nuclear energy in Ghana? History, science and policy. J. Soc Dev. Sci. (ISSN: 2221-1152) 8 (3), 11-34.

Agyekum, E.B., et al., 2019. Comparative evaluation of renewable energy scenario in ghana. IOP Conf. Ser.: Mater. Sci. Eng. 643, 012157. http://dx.doi.org/10. 1088/1757-899X/643/1/012157.

Amponsah, P.E., 2004. Seismic activity in Ghana: past, present and future. Ann. Geophys. 47 (2-3)

Anon, What is nuclear energy?: https://whatisnuclear.com/nuclear-energy.html. (Accessed 12 September 2019).

Anon, Ghana to introduce nuclear power into the energy mix, project to take 10 15 years: https://africabusinesscommunities.com/news/ghana-to-introducenuclear-power-into-the-energy-mix-project-to-take-10-15-years/. (Accessed 14 September 2019).

Anon, Nuclear energy for power production to begin 2029: https:/ gaecgh.org/nuclear-energy-for-power-production-to-begin-2029/. (Accessed 14 September 2019)

Anon, Milestones Approach: https://www.iaea.org/topics/infrastructuredevelopment/milestones-approach. (Accessed 14 September 2019).

Anon, Benefits and limitations of SWOT analysis: https://www.business qld.gov.au/starting-business/planning/market-customer-research/swotanalysis/benefits-limitations. (Accessed 17 November 2019).

Anon, Earthquake: http://thinkhazard.org/en/report/94-ghana/EQ. (Accessed 15 September 2019).

Anon, Is Africa Ready for Nuclear Energy?: https://www.iaea.org/newscenter news/is-africa-ready-for-nuclear-energy. (Accessed 17 November 2019).

Anon, Electricity from Ghana: http://www.gepcghana.com/electricity.php. (Accessed 17 September 2019).

Anon, See, for example, Transparency International, Frequently Asked Questions About Corruption. Available at www.transparency.org/news_room/faq/ corruption_faq. (Accessed 18 September 2019).

Anon, What is Vendor Financing?: https://corporatefinanceinstitute.com/ resources/knowledge/finance/vendor-financing/. (Accessed 19 September 2019).

Anon, Power Purchase Agreements (PPAs) and Energy Purchase Agreements (EPAs): https://ppp.worldbank.org/public-private-partnership/sector/energy/ energy-power-agreements/power-purchase-agreements. (Accessed 19 September 2019).

Arriola, L.R., 2009. Patronage and political stability in Africa. Comp. Political Stud. 42 (10), 1339-1362.

Barkatullah, N., Ahmad, A., 2017. Current status and emerging trends in financing nuclear power projects. Energy Strategy Rev. 18 (Dec), 127-140.

Birikorang, S.A., 2012. Prospects of nuclear power today as part of ghana energy mix and socio-economic development. Environ. Res. Eng. Manag. 2 (60) 67-76. http://dx.doi.org/10.5755/j01.erem.60.2.1109.

Border Crossings: https://www.easytrackghana.com/travel-information-ghana border-crossings.php. (Accessed 18 September 2019).

Bunn, Matthew, Corruption and Nuclear Proliferation. https://scholar.harvard. edu/files/matthew_bunn/files/corruption_and_nuclear_proliferation.pdf. (Accessed 18 September 2019).

Chen, W.M., Kim, H., Yamaguchi, H., 2014. Renewable energy in eastern asia: Renewable energy policy review and comparative SWOT analysis for promoting renewable energy in Japan, South Korea, and Taiwan. Energy Policy 74 (Nov), 319-329. 
Crawford, Guy, Ghana's Fossil-Fuel Subsidy Reform: https://www.ids.ac.uk/files/ dmfile/LHcasestudy09-FossilfuelsGhana.pdf. (Accessed 18 September 2019).

Debnath, K.B., Mourshed, M., 2018. Corruption significantly increases the capital cost of power plants in developing contexts. Front. Energy Res. 6 (Mar), 8. http://dx.doi.org/10.3389/fenrg.2018.00008.

Diawuo, F.A., et al., 2019. Disaggregation and characterization of residentia electricity use: Analysis for ghana. Sustainable Cities Soc. 48, 101586.

Duku, M.H., Gu, S., Hagan, E.B., 2011. A comprehensive review of biomass resources and biofuels potential in ghana. Renew. Sustain. Energy Rev. 15 (1), 404-415.

Efobi, K., Anierobi, C., 2014. Mass transportation system in Nigeria: Strategies for effective maintenance culture in public sector operations of Enugu State. J. Energy Tech. Policy 4, 14-19.

El Baradei, M., Nwogugu, E., Rames, J., 1995. International law and nuclear energy: Overview of the legal framework. IAEA Bull. 37 (3), 16-25, https: //www.iaea.org/sites/default/files/37302081625.pdf.

Levelized Cost of Energy Comparison-Unsubsidized Analysis: https: //www.lazard.com/media/450784/lazards-levelized-cost-of-energy-version120-vfinal.pdf. (Accessed 15 November 2019).

Ennison, I., Dzobo, M., 2018. Nuclear Power and Ghana'S Future Electricity Generation. IAEA-CN-164-1P01, IAEA Publication.

Nuclear Regulatory Authority of Ghana, http://gnra.org.gh. (Accessed 14 September 2019).

Ghana: Corruption Perception Index. https://www.transparency.org/country/ GHA. (Accessed 18 September 2019).

Energy Commission of Ghana Report (2018): http://www.energycom.gov. gh/planning/data-center/energy-outlook-for-ghana. Accra. (Accessed 17 September 2019).

Gyamfi, S., Diawuo, F.A., Kumi, E.N., Sika, F., Modjinou, M., 2018. The energy efficiency situation in Ghana. Renew. Sustain. Energy Rev. 82 (Feb), 1415-1423.

Gyamfi, S., Diawuo, F.A., Nyarko Kumi, E., Sika, F., Modjinou, M., 2018. The energy efficiency situation in Ghana. Renew. Sustain. Energy Rev. 82, 1415-1423. http://dx.doi.org/10.1016/j.rser.2017.05.007.

Hamami, S., Aloui, H., Chaker, N., Neji, R., 2015. SWOT analysis: Tunisian energy system. In: IREC2015 the Sixth International Renewable Energy Congress. IEEE, pp. 1-6.

Country Nuclear Power Profiles 2018 Edition, IAEA. https://www-pub.iaea. org/MTCD/Publications/PDF/cnpp2018/countryprofiles/Ghana/Ghana.htm. (Accessed 17 November 2019).

Ghana's Debt-to-GDP ratio to hit $62 \%$ by end of 2019 - IMF: https: //www.myjoyonline.com/business/2019/April-10th/ghanas-debt-to-gdpratio-to-hit-62-by-end-of-2019-imf.php. (Accessed 15 September 2019).

Ishola, F.A., et al., 2019. Sustainable energy exploration in Nigeria - a SWOT analysis. Proc. Manuf. 35, 1165-1171.

Kamran, M., et al., 2020. Towards empowerment of the renewable energy sector in Pakistan for sustainable energy evolution: SWOT analysis. Renew. Energy $146,543-558$.
Kebede, E., Kagochi, J., Jolly, C.M., 2010. Energy consumption and economic development in Sub-Sahara Africa. Energy Econ. 32 (3), 532-537. http: //dx.doi.org/10.1016/j.eneco.2010.02.003.

Kemausuor, F., et al., 2011. A review of trends, policies and plans for increasing energy access in Ghana. Renew. Sustain. Energy Rev. 15, 5143-5154.

Kumi, E.N., 2017. The Electricity Situation in Ghana: Challenges and Opportunities. Center for Global Development, Washington, DC, https://www.cgdev. org/publication/electricity-situation-ghana-challenges-and-opportunities.

Lei, Y., et al., 2019. SWOT analysis for the development of photovoltaic solar power in Africa in comparison with China. Environ. Impact Assess. Rev. 77 (Jul), 122-127.

Mari, C., 2014. The costs of generating electricity and the competitiveness of nuclear power. Prog. Nucl. Energy 73, 153-161.

Markovska, N., et al., 2009. SWOT analyses of the national energy sector for sustainable energy development. Energy 34, 752-756.

Medium Term Expenditure Framework (MTEF) for 2018-2021. 2018. Ministry of Energy, Accra. https://www.mofep.gov.gh/sites/default/files/pbb-estimates/ 2018/2018-PBB-NCCE.pdf.

Meierding, Emily, Energy Security and Sub-Saharan Africa, International Development Policy | Revue internationale de politique de développement [Online], 2 | 2011, Online since 14 2013, connection on 12 2019. URL: http: //journals.openedition.org/poldev/744; http://dx.doi.org/10.4000/poldev.744.

Mensah, J.T., Marbuah, G., Amoah, A., 2016. Energy demand in Ghana: A disaggregated analysis. Renew. Sustain. Energy Rev. 53 (Jan), 924-935.

Murphy, P., 2014. Types of Financing Structures. online: https://www.ifnec. org/ifnec/jcms/g_5916/finance-and-project-structuring-panel-review-offinancing-modelspaul-murphy. (Accessed 19 September 2019).

National Energy Policy 2010: http://www.purc.com.gh/purc/sites/default/files/ ENERGYPOLICY.pdf. (Accessed 17 November 2019).

New Uranium Mining Projects - Africa: https://www.wise-uranium.org/upafr html. (Accessed 15 September 2019).

(NEA), Impacts of the Fukushima Daiichi Accident on Nuclear Development Policies: https://www.oecd-nea.org/ndd/pubs/2017/7212-impactsfukushima-policies.pdf. (Accessed 16 November 2019).

Nyarko, B.J., Akaho, E.H., Ennison, I., 2009. Nuclear Power for Future Electricity Generation in Ghana: Issues and Challenges.

Phadermrod, B., Crowder, R.M., Wills, G.B., 2019. Importance-performance analysis-based SWOT analysis. Int. J. Inf. Manag. 144 (Feb), 194-203.

Ramana, M.V., Agyapong, P., 2016. Thinking big? Ghana, small reactors, and nuclear power. Energy Res. Soc. Sci. 21 (Nov), 101-113.

Reddy, A.K., et al., 2000. Energy and social issues. World Energy Assess. 44 (5), http://citeseerx.ist.psu.edu/viewdoc/download?doi=10111964978\&rep=rep1\& type $=$ pdf.

Schöbel, M., Klostermann, A., Lassalle, R., Beck, J., Manzey, D., 2017. Digging deeper! Insights from a multi-method assessment of safety culture in nuclear power plants based on Schein's culture model. Safety Sci. 95 (Jun), 38-49.

Terlikowski, P., Paska, J., Pawlak, K., Kaliński, J., Urbanek, D., 2019. Modern financial models of nuclear power plants. Prog. Nucl. Energy 110 (Jan), 30-33. 